\title{
Frequency of subgroups of the antigen "a" among volunteer donors
}

Katherine Parra-Jaramillo ${ }^{1}$ and Rosa F. Chiriboga-Ponce ${ }^{1,2}$

${ }^{1}$ Faculty of Medicine-Clinical Biochemistry Degree Program; ${ }^{2}$ Center of Research for health in Latin America, Pontificia Universidad Católica del Ecuador, Quito, Ecuador

\begin{abstract}
Introduction: The presence of weak variants of blood type A represents a challenge in the practice of immunohematology for discrepancies in the time of the classification. It is common in blood banks to perform a forward and reverse typing for the purpose of confirming the blood type, but not all the people with a subgroup A2 have developed anti-A1 antibodies. Objective: We present a descriptive, observational and transversal study that establishes the proportion of subgroups of $A$ antigen with the analysis of manual tube technique and monoclonal antibodies like anti-A, anti-A1 (Dolichus biflorus lectins extract) and anti-H. Methods: The analysis involved a total of 818 samples of voluntary blood donor, selected by random sampling, which were initially classified as 737 of Type $A$, and 81 as Type $A B$, with a confidence level of $95 \%$ (alpha error of $5 \%$ and $3 \%$ of precision). Results: The present study evaluated the existence of the subgroups A1, A2, A1B, A2B, A intermediate and A intB. Conclusions: It is recommended the identification of subgroups in different types of blood in the laboratory and blood banks.
\end{abstract}

KEY WORDS: Antigen A. Subgroup of A. Blood donors.

\section{Introduction}

Determining the presence of $A$ and $A B$ blood type subgroups will avoid problems not only at the blood transfusion level in blood banks, but also in cases of $\mathrm{ABO}$-incompatible transplantations that cause the socalled graft-versus-host disease ${ }^{1}$. Several studies demonstrate the importance of identifying antigen $A$ subgroups, due to the immunogenic capacity they exhibit, which stimulates the production of anti-A1 antibodies $^{2}$. In the present study, the existence of the A2 and $\mathrm{A} 2 \mathrm{~B}$ subgroup was identified; in addition, an $\mathrm{A}$ intermediate and $A$ intermediate $B$ was detected with a frequency of $4 \%$ and $0.5 \%$, respectively, which confirms that there is variability in blood group $A$ in the Ecuadorian population. Another important aspect was associating the presence of $A$ subgroups with the geographic place of origin, with a distribution of all A variants existing in the Imbabura province. These data are related to those reported in the literature, which mentions that the A subgroups are more common in the Black than in the Caucasian race ${ }^{3}$. An estimate of $3.6 \%$ of the black population, $2.0 \%$ of mulattos and country-wise, $75 \%$ of mestizos are settled in the Imbabura province ${ }^{4}$. The results of the subgroup variants we found corroborate what García mentions, "miscegenation or population mixture"3. This demonstrates the importance for $A$ antigens and subgroups detection to be instituted in blood donors who were initially typified as A in order to prevent alloimmunization and to avoid hemolytic anemia of the newborn in women ${ }^{5}$.

\section{Method}

This study is of the cross-sectional, descriptive type. A total of 818 blood donors were analyzed, out of which 737 were initially typified as $A$ and 81 as AB. Sample procurement: with good laboratory practice

\section{Correspondence:}

Rosa F. Chiriboga-Ponce

Avda. de la prensa 48-100 C.P. EC170103, Quito, Ecuador

E-mail: rfchiriboga@puce.edu.ec
Date of reception: 07-07-2016

Date of acceptance: 27-07-2016

DOI://dx.doi.org/10.24875/GMM.M18000106
Gac Med Mex. 2018;154:13-15

Contents available at PubMed www.gacetamedicademexico.com 
Table 1. Antigen A subgroups frequency with regard to blood donor's gender

\begin{tabular}{|c|c|c|c|c|c|c|c|c|c|c|c|c|c|}
\hline \multirow[t]{2}{*}{ Gender } & \multicolumn{2}{|c|}{ A1 } & \multicolumn{2}{|c|}{ A1B } & \multicolumn{2}{|c|}{ A2 } & \multicolumn{2}{|c|}{ A2B } & \multicolumn{2}{|c|}{ Aint } & \multicolumn{3}{|c|}{ AintB } \\
\hline & $\mathrm{n}$ & $\%$ & $\mathrm{n}$ & $\%$ & $\mathrm{n}$ & $\%$ & $\mathrm{n}$ & $\%$ & $\mathrm{n}$ & $\%$ & $\mathrm{n}$ & $\stackrel{\infty}{-}$ & $\%$ \\
\hline Female & 261 & 43.36 & 17 & 27.87 & 47 & 44.34 & 10 & 62.5 & 10 & 34.5 & 1 & $\stackrel{N}{\Sigma}$ & 25 \\
\hline Male & 341 & 56.64 & 44 & 72.13 & 59 & 55.66 & 6 & 37.5 & 19 & 65.5 & 3 & $\underset{\frac{c}{\sigma}}{\grave{c}}$ & 75 \\
\hline Total & 602 & 100.00 & 61 & 100 & 106 & 100 & 16 & 100 & 29 & 100 & 4 & हो & 100 \\
\hline
\end{tabular}

being adhered to, a segment was obtained of the tube of the red blood cell packs obtained from blood donors without producing ruptures or contamination of the red blood cell concentrate, thus obtaining the blood sample. During the study, there was no direct contact with the blood donor. Employed reagents: DiaClon immunoglobulin (Ig) M-type anti-A monoclonal antibodies for plates and tubes (Id. 10291), DiaClon IgM-type anti-B monoclonal antibodies for plates and tubes cell lines G1/2 (Id. 10301) and Bio-Rad anti-H lectin for in-tube test. Commercial cells: Diacell A1-A2, B (diapro) for quality control. Processing: all blood samples were diluted at $3 \%$ in saline prior to cell washing. Quality Control: following the protocol described in the article published by Franco and the American Association of Blood Banks Technical Manual6,7, the avidness, specificity and potency parameters of these reagents were assessed. For the $A 1$ and $B$ cells, characteristics such as appearance, color, turbidity and affinity were verified. Subgroup determination: the in-tube methodology was used; by means of agglutination reaction, the presence or absence of the different $A$ antigens was identified; a positive and a negative control were included foe each test; reading was carried out with a visualization lamp. Statistical analysis: descriptive statistics was used for data analysis, and to verify if there was association between two variables, Pearson's correlation test was employed. Ethical aspects: All donors signed an informed consent authorizing the performance of "all the required tests" for the use of the donated blood (FOS.10).

\section{Results}

The data analysis determined the existence of $A$ subgroups in the blood donors, with $\mathrm{A} 1$ being prevalent $(73 \%)$, followed by $A 2(13 \%)$; the presence of $A 1 B$ and $A 2 B$ was detected in a lower percentage $(8 \%$ and $2 \%$, respectively); an important finding was the existence of $A$ intermediate and $A$ intermediate $B$ subgroups, with a frequency of 4 and $0.5 \%$, respectively.

When the presence of antigen A subgroups was correlated with gender and age, subgroups $\mathrm{A} 1$ and $\mathrm{A} 1 \mathrm{~B}$ were established to be more common in the male gender, as well as A-intermediate and A-intermediate B. The A2B subgroup is more common in females; however, this relationship was not statistically significant $(p>0.05)$. Table 1 shows the existence of antigen A variants that give rise to the existence of 6 blood subgroups in the Ecuadorian population. The A subgroups age distribution analysis established that, between 17 and 49 years of age, there are $\mathrm{A}$ variants in $28.9 \%$ and $36.8 \%$, respectively. With these results, the search for anti-A1 antibodies was carried out, with only one donor being found to be alloimmunized. The analysis of red blood cell antigen $A$ subgroups distribution and the Ecuadorian blood donors place of origin was significant $(p<0.05)$ in subgroups $A 1$ and $A 2$; subgroups $A 1$ and $A 2 B$ are distributed in the Esmeraldas, Imbabura, Santo Domingo, Pichincha and Tulcán provinces, whereas A2, A2B and A-intermediate were localized in 3 Ecuadorian provinces and A-intermediate B only in the Pichincha province. Table 2 shows A subgroups distribution in Ecuadorian provinces with important population migration.

\section{Discussion}

The methods for blood selection and classification such as direct and inverse typing, antibody screening and irregular antibody identification are the processes that are commonly carried out in the country's blood banks ${ }^{12}$; however, $A$ and $A B$ blood subgroups typing is not systematically performed, since anti-A1 antibodies were considered to be alloantibodies; i.e., that they are produced after previous contact in $1 \%$ of people considered to be $\mathrm{A}^{7}$. However, several studies establish the importance of antigen A subgroups identification in post-transfusion reactions, hemolytic anemia of the newborn, and in renal and stem cell transplantations owing to the immunogenicity presented by these antigens by stimulating the production of anti-A1 antibodies ${ }^{2}$. One case of alloimmunization by incompatible blood transfusion was reported after the patient received a second $A B$ blood transfusion; initially, the he didn't suffer any hemolytic reaction; however, when he received incompatible blood again, he 
Table 2. Frequency of antigen A subgroups per province

\begin{tabular}{|c|c|c|c|c|c|c|c|c|c|c|}
\hline & \multicolumn{2}{|c|}{ Esmeraldas } & \multicolumn{2}{|c|}{ Imbabura } & \multicolumn{2}{|c|}{ Pichincha } & \multicolumn{2}{|c|}{$\begin{array}{c}\text { Sto. } \\
\text { Domingo }\end{array}$} & \multicolumn{2}{|c|}{ Tulcán } \\
\hline & $n$ & $\%$ & $\mathrm{n}$ & $\%$ & $\mathrm{n}$ & $\%$ & $\mathrm{n}$ & $\%$ & $\mathrm{n}$ & $\%$ \\
\hline A1 & 3 & 75.00 & 26 & 68.42 & 541 & 75.24 & 31 & 55.36 & 1 & 100 \\
\hline$A 1 B$ & 1 & 25.00 & 5 & 13.16 & 46 & 6.40 & 9 & 16.07 & & \\
\hline $\mathrm{A} 2$ & & & 3 & 7.89 & 95 & 13.21 & 8 & 14.29 & & \\
\hline A2B & & & 3 & 7.89 & 11 & 1.53 & 2 & 3.57 & & \\
\hline Aint & & & 1 & 2.63 & 22 & 3.06 & 6 & 10.71 & & \\
\hline AintB & & & & & 4 & 0.56 & & & & \\
\hline Total & 4 & 100 & 38 & 100 & 719 & 100 & 56 & 100.00 & 1 & 100 \\
\hline
\end{tabular}

experienced hemolytic anemia owing to the presence of anti-A1 IgG antibodies that were developed after the first transfusion 8 .

In the present study, the existence of subgroup $\mathrm{A} 2$ was determined in $13 \%$ of donors, $A 1 B$ in $8 \%, A 2 B$ in $2 \%$ and $A$-intermediate and $A$ intB at a frequency of 4 and $0.5 \%$, respectively, which confirms that there is antigen $A$ variability in the Ecuadorian population. Red blood cells that share type $\mathrm{A} 1$ and $\mathrm{A} 2$ characteristics are defined as A-intermediate, and are more common in the Black than in the Caucasian race. In this study, a prevalence of $4 \%$ was detected, just as in the study carried out in Cuba. This group A variant is relevant in population immunogenetics studies, and has contributed to the knowledge about population miscegenation with the Black race ${ }^{9}$. The presence of A blood group weak variants should also be considered as representing a challenge in the practice of transfusional medicine due to the discrepancies at the moment of typing ${ }^{9}$. The anti-A1 antibody is generally a cold agglutinin that atypically appears in the serum of A2 or A2B individuals lacking this antigen; however, in alloimmunization cases, clinically significant IgG-type antibodies are produced, which is highly common after blood transfusion or during pregnancy; at that moment, it turns into a hemolytic reaction-producing antibody, and it is therefore necessary for the donor and/or patient to know his/her true subgroup in order to prevent unnecessary alloimmunization?

Anti-A1 antibodies are found in between $1 \%$ and $2 \%$ in $\mathrm{A} 2$ people, and in $25 \%$ of $\mathrm{A} 2 \mathrm{~B}$ subjects ${ }^{10}$. In this study, a percentage of $1 \%$ was determined; the remaining $99 \%$ are not aloimmunized yet, and prevention is therefore important, with this being achieved by identifying the presence of $A$ subgroups. In this study, a distribution of $A$ subgroups in groups considered to be of reproductive age was determined. This is an important finding, since this is the young age group that comprises blood donors that can become repetitive volunteers; furthermore, it includes women of child-bearing age. All these variables turn into risk factors for alloimmunization, either by blood transfusion or pregnancy. The immune response that is produced against antigens of the $\mathrm{ABO}$ system ends up in complement activation, which elicits a hemolytic reaction that can be mild or serious $^{8,11}$. ABO system incompatibility during pregnancy is a common hematologic problem that is going to affect the newborn; it is usually benign, but if the mother has been previously alloimmunized, it can cause hemolytic anemia of the newborn ${ }^{3,11}$.

The presence of $A$ subgroups was also correlated with the place of origin, with a percentage of $A 1$ of $75 \%$ being found both in donors who were native to Esmeralda and Pichincha, with all $A$ variants being distributed in the Imbabura province. These data are consistent with those reported in the literature which refer that the A subgroups are more common in the Black than in the Caucasian race ${ }^{3}$. About $3.6 \%$ of the black population, $2.0 \%$ of mulattos and, country-wise, $75 \%$ of mestizos ${ }^{4}$ are estimated to be settled in the Imbabura province. The results of the identified subgroups variants corroborate what García refers, "miscegenation or population mixture"3. All these analyses demonstrate the importance for $A$ antigen and subgroups detection to be instituted not only in blood donors, but also in clinical laboratories, hospitals and transfusional medicine centers users in order to prevent alloimmunization?

\section{References}

1. Sassi M, Maggiore U, Buzio C, et al. Immunohaematological and apheretic aspects of the first kidney transplant from a living, ABO-incompatible donor carried out in Italy. Blood Transfus. 2011;9(2):218-24.

2. Akkök $C A$, Haugaa $H$, Galgerud $A$, et al. Severe hemolytic transfusion reaction due to anti-A1 following allogeneic stem cell transplantation with minor ABO incompatibility. Transfus Apher Sci. 2013;48(1):63-6.

3. García Rosasco M, Lippi S, Valverde J. Frecuencia de los grupos sanguíneos A1, A2, Aint, B y O en individuos normales. Rev Cubana Hematol Inmunol. 2001;17(3):171-4.

4. Instituto Nacional de Estadística y Censos (INEC), EMEDHINO, Indicador no publicado elaborado por el SIISE: Autoidentificación étnico-racial; 2000.

5. Daniels G, Bromilow I. Essential Guide to Blood Groups. Oxford: Wiley-Blackwell; 2013.

6. Franco E. El control de la calidad de los análisis inmunológicos en la región de las Américas. Revista Panamericana de la Salud. 2013;2:176-82.

7. American Association of Blood Banks. Manual Técnico AABB 17. ${ }^{a}$ Ed. Atlanta: American Association of Blood Banks; 2013.

8. Chaundy $\mathrm{R}$, Sonkar A. High titer Inmunizing anti-A1 in an $A 2 B$ patient Resulting in hemolytic transfusion reaction. Ind Medica. 2004;12(2):1-4.

9. Shastry $S$, Bhat $S$. Imbalance in A2 and A2B phenotype frequency of ABO group in South India. Blood Transfusion. 2010;8(4):267-70.

10. Zamudio-Godinez L. Reacciones transfusionales. Medigraphic. Gac Med Mex. 2003;139(3):1-4.

11. Aberláez-Gracia, C.A. Sistema de grupo sanguíneo ABO. Medicina \& Laboratorio. 2009;15:329-40.

12. González JL. Anticuerpos irregulares, su importancia en medicina transfusional. Revista Médica del IMSS, 2005; págs. 17-20. 